\title{
Preoperative Weight Reduction Using the Intragastric Balloon
}

\author{
Stephan Göttig Rudolf A. Weiner Markos Daskalakis \\ Center for Minimal-Invasive Surgery, Department of General and Bariatric Surgery, Krankenhaus Sachsenhausen, Frankfurt/M., \\ Germany
}

\section{Key Words}

Intragastric ballon · BioEnterics ${ }^{\circledR}$ Intragastric Balloon $\cdot \mathrm{BIB}^{\circledR}$. Preoperative weight reduction · Bariatric surgery

\section{Summary}

Background: Gastric balloon therapy (GBT) is a temporay, nonsurgical treatment for obesity. This retrospective study evaluates safety and efficacy of GBT in obese patients. Methods: The BioEnterics ${ }^{\circledR}$ Intragastric Balloon (BIB) was endoscopically implanted into each patient's stomach and inflated with saline $(450-750 \mathrm{ml})$. Extraction was planned after 6 months. Data from 190 patients receiving GBT were evaluated. Mean weight was $168.4 \pm 58.9 \mathrm{~kg}$ (range 76.5-310.0) and mean BMI was $55.6 \pm 17.5 \mathrm{~kg} / \mathrm{m}^{2}$ (range 27.0-95.7). Results: Mean weight loss at the time of balloon removal was $21.2 \pm 14.0 \mathrm{~kg}$ (range 0-80.0). The mean BMI loss and EBL (Excess BMI Loss) were $7.2 \pm 4.9 \mathrm{~kg} / \mathrm{m}^{2}$ (range $0-28.9$ ) and $30.1 \pm 26.4 \%(0-184.4)$, respectively. The most substantial weight and BMI loss was observed in the most massively obese patients. Minor complications at implantation were encountered in 2 cases $(1.1 \%)$ due to leakage of the balloon, and in 3 cases at explantation (1.6\%). No mortality or major complications such as gastric perforation or ulcers occurred. Of the 190 patients, 76 received subsequent surgery $(40.0 \%)$. Of those, 7 patients had a $\mathrm{BMI}<50 \mathrm{~kg} / \mathrm{m}^{2}$ while all other patients where super-obese $\left(\mathrm{BMI}>50 \mathrm{~kg} / \mathrm{m}^{2}\right) .58$ patients $(30.5 \%)$ with a $\mathrm{BMI}>60 \mathrm{~kg} / \mathrm{m}^{2}$ which had an extraordinary high operation risk were able to receive subsequent surgical treatment because of a substantial weight loss and/or reduced comorbidity. Conclusion: GBT appears to be a safe, tolerable, and potentially effective procedure for the initial treatment of morbid obesity.

\section{Introduction}

Among the different treatment options for obesity, the implantation of an intragastric balloon represents a temporary, nonsurgical intervention. Gastric balloon therapy (GBT) is considered to be a restrictive procedure that is completely reversible and repeatable at any time $[1,2]$. The intragastric balloon consists of a soft, flexible silicone elastomer which is implanted into the patient's stomach and filled with saline solution to a volume of approximately $700 \mathrm{ml}$ (fig. 1). Balloon placement and removal is performed under endoscopic control. The intragastric balloon is designed to mechanically provide a sensation of satiety, resulting in decreased food ingestion and facilitated learning of dietary and new behavioral routines [3]. It remains in the gastric cavity for a period of usually 6 months.

There are mainly two groups of patients for which GBT is indicated: patients who do not fulfill the criteria for bariatric surgery and super-obese patients $\left(\mathrm{BMI}>50 \mathrm{~kg} / \mathrm{m}^{2}\right)$ who have a high surgical risk due to their excessive weight. In these patients, weight reduction through GBT may help reduce severe comorbidities and surgical risks before subsequent bariatric or other surgery. It has been shown that a modest preoperative weight loss of 10-20\% reduces the complications of surgery [4].

This retrospective study evaluates the safety and efficacy of GBT with emphasis on preoperative weight reduction.

\section{Patients and Methods}

\section{Patients}

The BioEnterics ${ }^{\circledR}$ Intragastric Balloon $\left(\mathrm{BIB}^{\circledR}\right)$ (BioEnterics Corporation; Carpinteria, CA, USA) was used for all patients. Patients received GBT either as a preoperative procedure to reduce severe comorbidities and surgical risks or as an alternative upon refusal of conventional surgical treatment due to fear of complications. All patients had been obese for at least 5 years and had failed to achieve weight loss on an adequate weight control program for more than 3 years. All patients were screened for major endocrine disorders.

\section{KARGER \\ Fax +497614520714 (c) 2009 S. Karger GmbH, Freiburg \\ Accessible online at: www.karger.com}

Prof. Dr. med. Rudolf A. Weiner

Chirurgische Klinik, Krankenhaus Sachsenhausen

Schulstraße 31, 60594 Frankfurt, Germany

Tel. +49 $696605-1131$, Fax -12 03

rweiner@khs-ffm.de 


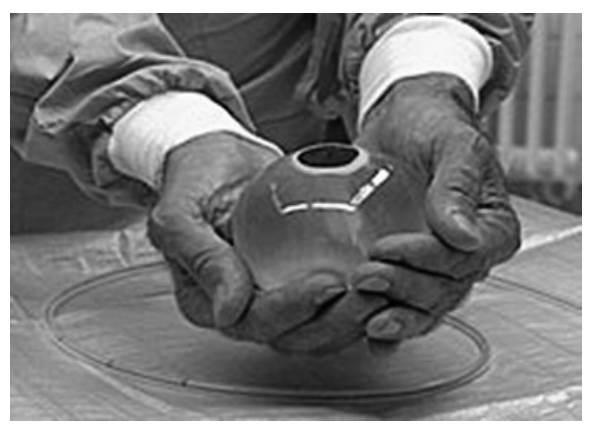

Table 1. Subgroup analysis of patient demographics, weight loss, and BMI change (mean values)

Fig. 1. Presentation of the BioEnterics Intragastric Balloon (BIB). The balloon was filled with saline solution to a volume of $600 \mathrm{ml}$. The radiopaque, self-sealing valve (dark) can be seen on top. Note that the BIB is implanted deflated into the patient's stomach and filled subsequently.

Exclusion criteria for GBT were: (1) age $<16$ and $>70$, (2) neoplasia, (3) pregnancy, (4) alcohol or drug abuse. Contraindications related more specifically to the balloon consisted of (5) previous bariatric or gastrointestinal surgery and (6) gastrointestinal lesions revealed by gastroscopy: neoplastic lesions, large hiatal hernia $(>5 \mathrm{~cm})$, grade III esophagitis, duodenal or gastric ulcer, lesions considered at risk for bleeding. Written informed consent was obtained from all treated patients.

\section{Balloon Insertion and Removal}

BIB insertion into the stomach was performed endoscopically under conscious sedation. Esophagus, stomach and duodenum were thoroughly inspected by gastroscopy to rule out any structural abnormalities. At implantation, the balloon was placed in the stomach and inflated under direct endoscopic vision with saline $/ 0.1 \%$ methylene blue $(450-750 \mathrm{ml})$. Once able to tolerate oral fluids, patients were discharged from the hospital with a regular proton pump inhibitor and, if required, spasmolytic and anti-emetic medication.

The patients were advised to observe a fully liquid diet for the first week, progress to half-solid food during the second week, and then continue with regular meals under specific dietary instructions by a dietitian. Follow-up regarding tolerance and efficacy evaluation as well as patients' eating protocol and quality of life questionnaire assessment were performed at 1, 3 and 6 months after balloon insertion. Patients were evaluated by a multidisciplinary team consisting of a bariatric surgeon, an internist, a dietician, and a physiotherapist. Balloon removal was routinely planned after 6 months. Under conscious sedation, diagnostic endoscopy was performed and the BIB was removed.

\section{Results}

\section{Patient Demographics}

Data from all patients receiving GBT in the period from February 2002 to May 2008 were collected. The BIB was implanted in 190 patients. Of these patients, 97 were female and 93 were male, with a mean age of $39.0 \pm 9.6$ years (range 16-63). Mean weight and BMI were $168.4 \pm 58.9 \mathrm{~kg}$ (range $76.5-310.0$ ) and $55.6 \pm 17.5 \mathrm{~kg} / \mathrm{m}^{2}$ (range 27.0-95.7), respectively. 12 patients (5.8\%) had a BMI $\left(\mathrm{kg} / \mathrm{m}^{2}\right)$ of $25-30,21$ patients $(10.5 \%)$ had a BMI of 30-35, 28 patients $(14.7 \%)$ had a BMI of $35-40,20$ patients $(10.5 \%)$ had a BMI of $40-50,15$ patients $(7.9 \%)$ had a BMI of $50-60,51$ patients (26.8\%) had a BMI of $60-70,29$ patients $(15.3 \%)$ had a BMI of $70-80$, and 14 patients $(7.4 \%)$ had a BMI $>80$ (table 1$)$.

\section{Balloon Implantation and Removal}

Complications at implantation were encountered in 2 cases $(1.1 \%)$ with leakage of the balloon due to agitated patients pulling at the endoscope. New balloons were implanted in a second attempt. In the first week after implantation, almost $90 \%$ of the patients experienced vomiting, nausea, abdominal pain, or dysphagia. The symptoms disappeared or decreased remarkably after the first week in all but 23 cases, and in 4 of those patients after the third week. Early balloon removals because of intolerance were performed in 19 cases $(10.0 \%)$. All side effects disappeared after balloon removal. The mean period of BIB treatment was $171 \pm$ 69 days (range $1-415$ ).

The endoscopic deflation and removal of the balloon was uneventful in all but 3 cases (1.6\%): in 2 cases, extraction had to be performed in a second session due to a filled stomach with the risk of aspiration in one patient and respiratory depression treated with oxygen and benzodiazepine antagonist in the other patient. In the third patient, balloon extraction had to be performed in unconscious sedation with endotracheal intubation because of intolerance of the removal procedure in conscious sedation.

\section{Weight Loss}

Overall mean weight loss at the time of balloon removal was $21.2 \pm 14.0 \mathrm{~kg}$ (range 0-80.0). The overall mean BMI loss and EBL (Excess BMI Loss) were $7.2 \pm 4.9 \mathrm{~kg} / \mathrm{m}^{2}$ (range 0-28.9) and $30.1 \pm 26.4 \%$ (0-184.4), respectively. 40 patients (21.1\%) lost more and 69 patients $(36.3 \%)$ lost less than $20.0 \%$ of their excess BMI, while 10 of these patients $(5.3 \%)$ did not lose weight at all due to noncompliant eating behavior. Subgroup analysis of weight loss and BMI change is shown in table 1. The most substantial BMI loss was observed in the most massively obese patients. Weight loss and BMI loss were generally increasing with a higher pretreatment BMI. In contrast, EBL was higher in the group with BMI 25-30 and lowest in the group with a BMI $>80$.

\section{Preoperative Weight Reduction}

Of the 190 patients, 76 (40.0\%) received subsequent surgery: Roux-en-Y gastric bypass $(n=33)$, sleeve gastrectomy $(n=22)$, bi- 


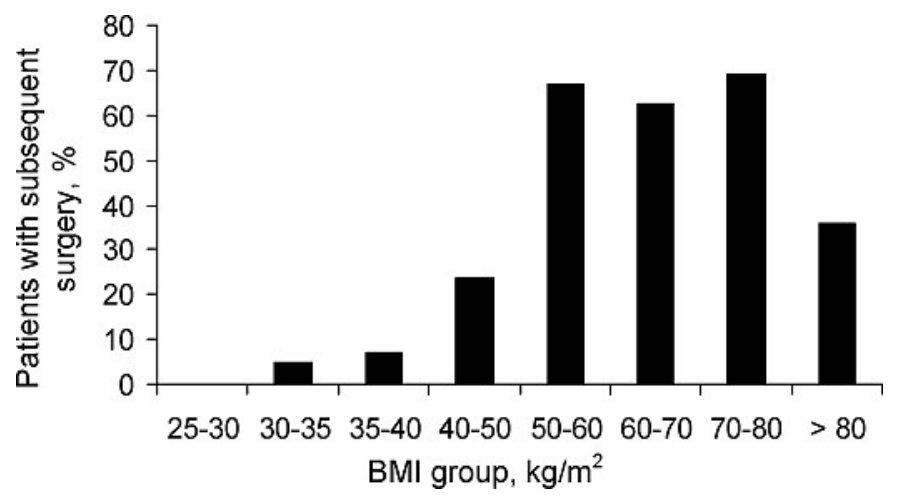

Fig. 2. Percentage of patients receiving subsequent surgery.

liopancreatic diversion $(\mathrm{n}=17)$, and adjustable gastric band $(n=4)$. All the procedures were performed laparoscopically. Of these 76 patients, 7 patients receiving subsequent surgery had a $\mathrm{BMI}<50 \mathrm{~kg} / \mathrm{m}^{2}$ while all other patients were super-obese (BMI $>50 \mathrm{~kg} / \mathrm{m}^{2}$ ) (fig. 2). More than $60 \%$ of patients with an initial BMI of $50-80 \mathrm{~kg} / \mathrm{m}^{2}$ underwent bariatric surgery, whereas only $35 \%$ ( 5 out of 14 ) of the patients with a BMI $>80 \mathrm{~kg} / \mathrm{m}^{2}$ were operated. 58 patients $(30.5 \%)$ with a BMI $>60 \mathrm{~kg} / \mathrm{m}^{2}$, which could not receive bariatric surgery due to an extraordinary high operation risk, could achieve an 'operable state' through substantial weight loss and/or reduced comorbidities.

\section{Discussion}

The aim of this retrospective study was to investigate the safety, efficacy, and preoperative weight reduction of intragastric balloon therapy. The results indicate that BIB insertion is a safe, tolerable, and potentially effective procedure for the initial treatment of morbid obesity.

\section{Efficacy and Safety of GBT}

There were minimal complications associated with balloon placement and removal ( $0.9 \%$ and $2.8 \%$, respectively). No mortality occurred in our cohort. Furthermore, no major complication such as balloon deflation, intestinal obstruction, or gastric perforation occurred in our patients. In agreement with our results, a meta-analysis of 15 studies analyzing more than 3,600 patients confirmed the safety of GBT [5].

Compared to other BIB studies, we achieved a moderate, though above-average weight loss of $21.2 \pm 14.0 \mathrm{~kg}$ with a mean BMI loss and EBL of $7.2 \pm 4.9 \mathrm{~kg} / \mathrm{m}^{2}$ and $30.1 \pm 26.4 \%$, respectively [6]. BIB is a temporary anti-obesity treatment which induces only a shortterm weight loss [7]. Several studies have shown that weight loss reverses after balloon removal [8-10]. Analysis of the long-term weight loss has shown that the patients regain $40 \%$ of their pretreatment excessive weight 1 year after BIB explantation [6]. GBT does not seem to be an alternative to surgery for individuals with morbid obesity as it is designed to remain in the stomach for only 6 months. Compared to surgical treatment, GBT can be attractive to patients as it is less invasive than surgery.
Preoperative Weight Reduction with GBT

Until today, the only effective long-term treatment for extreme obesity is bariatric surgery. Although the introduction of laparoscopy to the field of bariatric surgery has improved results and reduced complications, the operative management of super-obese patients presents a major technical challenge for both surgeons and anesthetists. Extreme obesity causes difficulties in intubation and mechanical ventilation during anesthesia [11, 12]. Surgical technical difficulties increase the risk of perioperative complications and are related to: (1) thick abdominal walls hindering control of laparoscopic instruments and complication of the necessary surgical maneuvers; (2) excessive omental and intra-abdominal fat deposition causing an undersized operation field with a limited field of vision; (3) hepatomegaly resulting in difficult liver retraction and constrained exposure [13-15]. Conversions to open surgery in super-obese patients are more frequently related to technical difficulties $[8,15]$.

Preoperative weight loss is probably the most important method for reducing surgical risks in extremely obese patients $[16,17]$. It has been shown that a modest preoperative weight loss of 10-20\% reduces complications [4]. GBT before a surgical procedure may reduce operative risks, regardless of whether the surgery is bariatric or not. Our results suggest that even a partial weight loss $(21.2 \pm 14.0 \mathrm{~kg})$ improves the surgical risk and reduces the technical difficulties of a laparoscopic approach to extremely obese patients. After BIB treatment, 58 super-obese patients with a $\mathrm{BMI}>60 \mathrm{~kg} / \mathrm{m}^{2}$ and a considerably high operation risk were able to receive subsequent surgical treatment because of a substantial weight loss and/or reduced comorbidity. All of them received laparoscopic bariatric surgery successfully; no conversion to open surgery was necessary.

After balloon removal, definitive surgery has to follow about 12 weeks thereafter (stomach edema, changing stomach size after BIB treatment). The eating disorders are still present, the capacity of the stomach is again increased, and the patients are able to continue their food intake without limitation. The optimal individual surgical treatment for each obese patient remains a challenge since there are no real guidelines. The BIB may help to decide whether a restrictive or a malabsorptive surgical operation is more appropriate. Patients relying solely on the BIB for weight loss without changing their eating behavior may benefit more from nonrestrictive bariatric operation such as gastric bypass or biliopancreatic diversion [18, 19].

In conclusion, GBT represents a useful but temporary way of achieving a vital BMI improvement in extremely obese patients, particularly as a first step before a definitive anti-obesity operation. When applied in specialized institutions with long-standing experience in the treatment of obesity, the BIB can be safely placed even in these high-risk obese patients. The implementation of GBT in a multidisciplinary setting is of imperative value.

\section{Disclosure}

The authors declared no conflict of interest. 


\section{References}

1 Genco A, Bruni T, Doldi SB, Forestieri P, Marino M, Busetto L, Giardiello C, Angrisani L, Pecchioli L, Stornelli P, Puglisi F, Alkilani M, Nigri A, Di Lorenzo N, Furbetta F, Cascardo A Cipriano M, Lorenzo M, Basso N: BioEnterics Intragastric Balloon: The Italian experience with 2,515 patients. Obes Surg 2005;15:1161-1164.

2 Fernandes M, Atallah AN, Soares BG, Humberto S, Guimarães S, Matos D, Monteiro L, Richter B: Intragastric balloon for obesity. Cochrane Database Syst Rev 2007;1:CD004931. www.cochrane.org/reviews/en/ab004931.html.

-3 Martinez-Brocca MA, Belda O, Parejo J, Jimenez L, del Valle A, Pereira JL, Garcia-Pesquera F, Astorga R, Leal-Cerro A, Garcia-Luna PP: Intragastric balloon-induced satiety is not mediated by modification in fasting or postprandial plasma ghrelin levels in morbid obesity. Obes Surg 2007;17:649-657.

4 Pasulka PS, Bistrian BR, Benotti PN, Blackburn GL: The risks of surgery in obese patients. Ann Intern Med 1986;104:540-6.

5 Imaz I, Martínez-Cervell C, García-Alvarez EE, Sendra-Gutiérrez JM, González-Enríquez J Safety and effectiveness of the intragastric balloon for obesity. A meta-analysis. Obes Surg 2008;18:841-846.

6 Dumonceau JM: Evidence-based review of the Bioenterics Intragastric Balloon for weight loss. Obes Surg 2008;18(12):1611-1617.
Genco A, Cipriano M, Bacci V, Cuzzolaro M, Materia A, Raparelli L, Docimo C, Lorenzo M, Basso N: Bioenterics Intragastric Balloon (BIB): a short-term, double-blind, randomised, controlled, crossover study on weight reduction in morbidly obese patients. Int J Obes 2006;30:129133.

8 Weiner R, Gutberlet H, Bockhorn H: Preparation of extremely obese patients for laparoscopic gastric banding by gastric-balloon therapy. Obes Surg 1999;9(3):261-264.

$\checkmark 9$ Mathus-Vliegen EM, Tytgat GN: Intragastric balloon for treatment-resistant obesity: safety, tolerance, and efficacy of 1-year balloon treatment followed by a 1-year balloon-free follow-up. Gastrointest Endosc 2005;61(1):19-27.

10 Herve J, Wahlen $\mathrm{CH}$, Schaeken A, Dallemagne B, Dewandre JM, Markiewicz S, Monami B, Weerts J, Jehaes C: What becomes of patients one year after the intragastric balloon has been removed? Obes Surg 2005;15(6):864-870.

11 Ogunnaike BO, Jones SB, Jones DB, Provost D, Whitten CW: Anesthetic considerations for bariatric surgery. Anesth Analg 2002;95:1793-805.

12 Sprung J, Whalley DG, Falcone T, Wilks W, Navratil JE, Bourke DL: The effects of tidal volume and respiratory rate on oxygenation and respiratory mechanics during laparoscopy in morbidly obese patients. Anesth Analg 2003;97:268-274.

13 Frutos MD, Morales MD, Luján J, Hernández Q, Valero G, Parrilla P: Intragastric balloon reduces liver volume in super-obese patients, facilitating subsequent laparoscopic gastric bypass. Obes Surg 2007;17(2):150-154.
Alfalah H, Philippe B, Ghazal F, Jany T, Arnalsteen L, Romon M, Pattou F: Intragastric balloon for preoperative weight reduction in candidates for laparoscopic gastric bypass with massive obesity. Obes Surg 2006;16(2):147-150.

5 Busetto L, Segato G, De Luca M, Bortolozzi E, MacCari T, Magon A, Inelmen EM, Favretti F, Enzi G: Preoperative weight loss by intragastric balloon in super-obese patients treated with laparoscopic gastric banding: a case-control study. Obes Surg 2004;14:671-676.

16 Alvarado R, Alami RS, Hsu G, Safadi BY, Sanchez BR, Morton JM, Curet MJ: The impact of preoperative weight loss in patients undergoing laparoscopic Roux-en-Y gastric bypass. Obes Surg 2005;15:1282-1286.

17 Liu RC, Sabnis AA, Forsyth C, Chand B: The effects of acute preoperative weight loss on laparoscopic Roux-en-Y gastric bypass. Obes Surg 2005;15:1396-1402.

18 Loffredo A, Cappuccio M, De Luca M, de Werra C, Galloro G, Naddeo M, Forestieri P: Three years experience with the new intragastric balloon, and a preoperative test for success with restrictive surgery. Obes Surg 2001;11:330-333.

19 Doldi SB, Micheletto G, Perrini MN, Librenti MC, Rella S: Treatment of morbid obesity with intragastric balloon in association with diet. Obes Surg 2002;12:583-587. 